\title{
Prognostic significance of six clinicopathological features for biochemical recurrence after radical prostatectomy: a systematic review and meta-analysis
}

\author{
Haoran Liu ${ }^{1,2, *}$, Hui Zhou ${ }^{1,2, *}$, Libin Yan ${ }^{1,2}$, Tao Ye ${ }^{1,2}$, Hongyan Lu ${ }^{1,2}$, Xifeng Sun ${ }^{1,2}$, \\ Zhangqun $\mathrm{Ye}^{1,2}$ and Hua $\mathrm{X} \mathbf{u}^{1,2}$ \\ ${ }^{1}$ Department of Urology, Tongji Hospital, Tongji Medical College, Huazhong University of Science and Technology, Wuhan \\ 430030, China \\ ${ }^{2}$ Institute of Urology, Tongji Hospital, Tongji Medical College, Huazhong University of Science and Technology, Wuhan \\ 430030, China \\ "These authors contributed equally to this work \\ Correspondence to: Hua XU, email: xuhuawhu@163.com \\ Keywords: clinicopathological features; biochemical recurrence; prostate cancer; radical prostatectomy; meta-analysis \\ Received: November 30, 2016 Accepted: October 11, 2017 Epub: November 06, 2017 Published: August 14, 2018
}

Copyright: Liu et al. This is an open-access article distributed under the terms of the Creative Commons Attribution License 3.0 (CC BY 3.0), which permits unrestricted use, distribution, and reproduction in any medium, provided the original author and source are credited.

\section{ABSTRACT}

Identifying patients with high risk of biochemical recurrence after radical prostatectomy is of immense value in clinical practice. Assessment of prognostic significance of specific clinicopathological features plays an important role in surgical management after prostatectomy. The purpose of our meta-analysis was to investigate the association between the six pathological characteristics and the prognosis of prostate cancer. We carried out a systematic document retrieval in electronic databases to sort out appropriate studies. Outcomes of interest were gathered from studies comparing biochemical recurrence-free survival (BCFS) in patients with the six pathological traits. Studies results were pooled, and hazard ratios (HRs) combined with corresponding $95 \%$ confidence intervals (CIs) for survival were used to estimate the effect size. 29 studies (21,683 patients) were enrolled in our meta-analysis. All the six predictors were statistically significant for BCFS with regard to seminal vesicle invasion $(H R=1.97,95 \% C I=1.79-2.18, p<0.00001)$, positive surgical margin $(H R=1.79,95 \% C I=1.56-2.06, p<0.00001)$, extracapsular extension $(H R=2.03,95 \% C I=1.65-2.50, p<0.0001)$, lymphovascular invasion $(H R=1.85$, $95 \% \mathrm{CI}=1.54-2.22, p<0.00001)$, lymph node involvement $(\mathrm{HR}=1.88,95 \% \mathrm{CI}=$ $1.37-2.60, p=0.0001)$ and perineural invasion $(H R=1.59,95 \% C I=1.33-1.91, p$ $<0.00001)$. Subgroup analysis showed that all the six predictors had significantly relationship with poor BCFS. The pooled results demonstrated that the six clinical findings indicated a worse prognosis in patients with prostate cancer. In conclusion, our results show several clinicopathological characteristics can predict the risk of biochemical recurrence after radical prostatectomy. Prospective studies are needed to further confirm the predictive value of these features for the prognosis of prostate cancer patients after radical prostatectomy.

\section{INTRODUCTION}

As one of the most common cancers for men around the world, prostate cancer causes great mortality and morbidity to patients [1]. Although a large proportion of these patients suffer low-risk, relatively indolent tumors that have little chance to progress or require surgical treatment, quite a few prostate cancers present with highrisk tumor characteristics. Clinically localized prostate cancers are best managed by radical prostatectomy (RP), while the advanced diseases always miss the opportunities and have to undergo the androgen-deprivation therapy 
or other adjuvant therapies [2, 3]. However, there is considerable possibility of disease recurrence after RP [4]. Thus, identifying patients with high risk of recurrence after RP is of immense value in clinical practice, so the prognosis of patients can be evaluated better and the illness can be managed timely and effectively. PSAdefined biochemical recurrence (BCR) always antedates clinical detectable distal metastasis and cancer specific mortality, providing the opportunity to access the optimal timing for salvage treatment modalities. Accurate prediction of biochemical recurrence can thus facilitate clinical decision making for prostate cancer patients [5]. Several clinicopathological factors are well established for predicting the BCR and clinical progression, including preoperative serum PSA, biopsy Gleason score, and clinical pathological stage. Some associated predictive tools which rely on certain preoperative variables are also developed to better evaluate the BCR, metastatic progression and mortality. However, these predictive variables can only provide an approximation of disease severity, there is still doubting whether additional variables can integrate with well-established ones to increase the reliability of current prognostic tools. Meticulous clinicopathological examinations will be done for resected tissue samples after RP, offering us a systematic evaluation of the characteristics of tumor. It is an intriguing problem if we can utilize certain histopathologic findings to better predict the BCR of prostate cancer patients after RP.

One of the main challenges for urologists and pathologists is the identification of potential prognostic factors in RP specimens to predict cancer progression and mortality. Apart from conventional indicators such as tumor volume, histological type, pathological Gleason score, and TNM stage, some microscopic evaluated factors are not sufficiently studied to demonstrate their prognostic value. Prostate cancer cells can invade the muscular wall of the extraprostatic part of the seminal vesicle, periprostatic fat, surrounding perineural sheath, lymph nodes, or vessel invasion (lymphatic or venous), resulting in seminal vesicle invasion (SVI), extracapsular extension (ECE), perineural involvement (PNI), lymph node involvement (LNI), or lymphovascular invasion (LVI) respectively [6, 7]. Positive surgical margin (PSM) is defined as neoplastic cells existed at the inked margin. The detection of SVI, ECE, PNI, LNI, LVI or PSM always indicates the expansion and dissemination of carcinoma, and may accompany with dismal results and high biochemical recurrence (BCR) incidence [8]. Whether the six clinicopathological features can become significant predictors of prognosis of prostate cancer after $\mathrm{RP}$ is a precious exploration. In order to identify more predictive factors from pathological evaluation to facilitate the clinical management, we performed this systematic review and meta-analysis of published papers to explore these specific features and their impacts on the BCR of prostate cancer after RP.

\section{RESULTS}

\section{Study selection and characteristics}

Based on the searching strategies, a total of 518 studies (274 from Pubmed, 240 from Embase, 4 from cochrane, 0 from $\mathrm{CNKI}$ ) were screening to determine their eligibility. 121 overlapped studies were excluded and there were 397 studies left. After carefully reviewed the titles and abstracts of all identified studies, we abnegated 266 articles whose types did not meet our requirements, such as reviews, editorials, comments, non-English articles or irrelevant topics. Eventually, 29 full publications met our eligibility criteria [6, 7, 9-35]. The PRISMA study selection diagram is shown in Figure 1.

The majority of identified studies examined the prognostic value of SVI, PSM, ECE, LVI, LNI, PIN on prostate cancer prognosis. The details of each study design and clinicopathological characteristics can be seen in Table 1, and pathological findings in each studies could be seen in Supplementary Table 1. The histopathological examination was done on the specimens from resected tumors. Most of the studies used the biochemical recurrence free survival (BCFS) rates to evaluate the prognostic value of six clinicopathological indicators to survival, and then BCFS was used as a common endpoint for further evaluation.

\section{Prognostic values of six clinicopathological features in prostate cancer after RP}

Hazard ratios (HRs) and 95\% confidence intervals (CIs) respectively of univariate and multivariate Cox proportional hazard regression models of 29 literatures were listed in Supplementary Table 1. Meanwhile, the pooled HRs and 95\% CIs for each clinicopathological feature are listed in Table 2. Our pooled results showed that all the six predictors were statistically significant for BCFS, the total analyses results were as follows: SVI (pooled HR:1.97 (1.79-2.18), $p<0.00001$, Figure 2), PSM (pooled HR:1.79 (1.56-2.06), $p<0.00001$, Figure 3), ECE (pooled HR: 2.03 (1.65-2.50), $p<0.0001$, Figure 4), LVI (pooled HR:1.85 (1.54-2.22), $p<0.00001$, Figure 5), LNI (pooled HR: 1.88, (1.37-2.60), $p=0.0001$, Figure 6), PNI (pooled HR:1.59 (1.33-1.91), $p<0.00001$, Figure 7).

\section{Study heterogeneity and publication bias}

Heterogeneity was assessed mainly by forest plots and $\mathrm{I}^{2}$ statistics. Inspection of forest plots did not reveal substantial heterogeneity. In our meta-analysis, investigation of publication bias by funnel plots showed no substantial funnel plot asymmetry for prognosis of six predictors, suggesting no presence of significant publication or selection bias. The details were shown in Supplementary Figure 1A-1F. 
Table 1: Baseline characteristics of eligible studies

\begin{tabular}{|c|c|c|c|c|c|c|c|c|c|c|c|c|}
\hline Study & Country & Period & $\begin{array}{l}\text { Study } \\
\text { design }\end{array}$ & $\begin{array}{c}\text { Consecutive } \\
\text { patients }\end{array}$ & $\begin{array}{l}\text { definition of } \\
\text { Survival }\end{array}$ & $\begin{array}{c}\text { No. of } \\
\text { patients }\end{array}$ & $\operatorname{Age}(y)$ & $\begin{array}{c}\text { Operative } \\
\text { procedures }\end{array}$ & $\begin{array}{l}\text { Adjuvant } \\
\text { therapy }\end{array}$ & $\begin{array}{c}\text { pre-Operative PSA } \\
(\mathbf{n g} / \mathbf{m l})\end{array}$ & Follow up (mo) & $\begin{array}{l}\text { NOS } \\
\text { score }\end{array}$ \\
\hline Antonarakis, 2012 [14] & USA & $2002-2004$ & $\mathrm{R}$ & yes & No & 57 & $58(42-75)^{*}$ & $\mathrm{RP}$ & Docetaxel & $7.6(2.2-32.2)^{*}$ & $37.4(10.4-44.5)^{x}$ & 7 \\
\hline Brooks, 2006 [15] & USA & 1991-2001 & $\mathrm{R}$ & NA & yes & 160 & $63(45-74)^{x}$ & $\mathrm{RP}$ & RT & NA & 99.6 & 7 \\
\hline Cheng, 2005 [16] & USA & $1990-1998$ & $\mathrm{R}$ & NA & No & 504 & NA & $\mathrm{RP}$ & No & NA & $44(1.5-144)$ & 6 \\
\hline Cho, 2011 [17] & Korea & $2005-2010$ & $\mathrm{R}$ & NA & No & 259 & $64.4(49-80)^{*}$ & $\mathrm{RP}$ & no & $19.6(0.8-173.6)^{x}$ & $40(6-63)^{*}$ & 8 \\
\hline Engers, 2007 [18] & Germany & NA & $\mathrm{R}$ & NA & No & 60 & $67(55-79)^{*}$ & RP & no & $14.4 \pm 12 \dagger$ & $86.4(24-172.8)^{*}$ & 6 \\
\hline Gannon, 2013 [19] & Canada & $1992-2005$ & $\mathrm{R}$ & NA & yes & 1826 & $62.4 \pm 5.7^{\dagger}$ & $\mathrm{RP}$ & NET & $7.2(5.0-11.6)^{*}$ & $90.9 \pm 43.8^{4}$ & 8 \\
\hline Herman, 2000 [20] & USA & 1983-1997 & $\mathrm{R}$ & NA & no & 263 & $64^{+}$ & $\mathrm{RP}+\mathrm{LA}$ & no & NA & $36(1-158)^{*}$ & 6 \\
\hline Huang, 2007 [6] & China & $2000-2005$ & $\mathrm{R}$ & NA & No & 126 & $67.8 \pm 5.7^{\dagger}$ & $\mathrm{RP}$ & no & $\mathrm{NA}$ & 26.7 & 7 \\
\hline Ito, 2002 [21] & Japan & $1989-1998$ & $\mathrm{R}$ & NA & No & 259 & $66.5(56-74)^{\circ}$ & $\mathrm{RP}+\mathrm{LA}$ & no & NA & $21.7(9-84.2)^{\circ}$ & 7 \\
\hline Jeon, 2009 [22] & Korea & $1995-2004$ & $\mathrm{R}$ & NA & No & 237 & $64.5(44-86)^{*}$ & $\mathrm{RP}$ & no & $11.5(0.2-98)^{n}$ & $41.4(1-141.4)^{*}$ & 8 \\
\hline Jung, 2011 [23] & Korea & 2005-2009 & $\mathrm{R}$ & NA & No & 407 & $63.24(38-82)^{*}$ & RALP+LA & no & $10.03(2.7-83.2)^{*}$ & $18.43(6-50)^{x}$ & 8 \\
\hline Kristiansen, 2013 [24] & Sweden & $1998-2005$ & $\mathrm{R}$ & NA & No & 1050 & $62.3(45-78)^{*}$ & $\mathrm{RP}$ & nо & $8.0(0.5-112)^{*}$ & $44.7(1-144)^{x}$ & 6 \\
\hline $\mathrm{Ku}, 2011[25]$ & Korea & $1997-2009$ & $\mathrm{R}$ & NA & No & 199 & $67.0(46-80)^{*}$ & $\mathrm{RP}+\mathrm{LA}$ & no & $12.6(1.5-357)^{*}$ & $37.0(1.0-143.0)^{x}$ & 7 \\
\hline Lee, 2005 [26] & USA & $1989-2000$ & $\mathrm{R}$ & NA & No & 557 & $64(59-68) /$ & $\mathrm{RP}$ & no & $7.8(5.3-12.1)^{*}$ & $91.2 \pm 34.8^{+}$ & 7 \\
\hline Loeb, 2006 [27] & USA & 1989-2004 & $\mathrm{R}$ & No & No & 1709 & NA & $\mathrm{RP}$ & no & $5.8 / 4.5$ & $74(0-159)^{*}$ & 6 \\
\hline Loeb, 2009 [7] & USA & $2002-2007$ & $\mathrm{R}$ & NA & no & 1256 & $56.1 \pm 6.7^{\dagger}$ & $\mathrm{RP}$ & no & $5.7 \pm 3.7^{\dagger}$ & $33.6(0-84)^{\circ}$ & 8 \\
\hline Luo, 2012 [28] & China & $1998-2010$ & $\mathrm{R}$ & NA & no & 117 & $61.2(52-76)^{\circ}$ & $\mathrm{RP}$ & no & NA & $49.8(5.1-91.8)^{*}$ & 6 \\
\hline May, 2006 [29] & Germany & 1996-2003 & $\mathrm{R}$ & NA & no & 412 & $63.7(44-79)^{*}$ & $\mathrm{RP}$ & no & $12.1(0.1-151)^{\circ}$ & $52.5(10-116)^{\circ}$ & 7 \\
\hline Meeks, 2013 [30] & USA & 1998-2011 & $\mathrm{R}$ & NA & no & 206 & NA & SRP & EBRT & 4.5 & NA & 6 \\
\hline Miyake, 2012 [31] & Japan & 2001-2008 & $\mathrm{R}$ & yes & no & 959 & $67.5 \pm 5.2^{\dagger}$ & $\mathrm{RP}$ & no & $10.5 \pm 6.2^{4}$ & 48.9 & 9 \\
\hline Oh, 2011 [32] & Korea & $2003-2008$ & $\mathrm{R}$ & NA & no & 534 & $64.9 \pm 6.7^{\dagger}$ & $\mathrm{RP}$ & no & $11.9 \pm 12.2^{\dagger}$ & $51.2 \pm 13.5$ & 7 \\
\hline Preston, 2010 [33] & Canada & $1985-2008$ & $\mathrm{R}$ & yes & no & 6855 & $(58.5-73.3)$ & RP & no & $(3.3-11.2)$ & $37.3(14.9-71.6)^{*}$ & 8 \\
\hline Quinn, 2001 [9] & Australia & $1986-1999$ & $\mathrm{R}$ & NA & no & 732 & $62.1(40-76)^{\circ}$ & $\mathrm{RP}$ & no & $13.0(0.7-194)^{*}$ & $41.1(1.0-167.7)^{*}$ & 6 \\
\hline Shariat, $2004[10]$ & USA & 1994-2002 & $\mathrm{R}$ & NA & no & 630 & $60.9(40-75)^{\circ}$ & $\mathrm{RP}+\mathrm{LA}$ & no & $6.1(0.1-99.0)^{*}$ & $21.4(1.0-101.3)^{\circ}$ & 6 \\
\hline Turker, 2010 [11] & Turkey & $1993-2009$ & $\mathrm{R}$ & NA & no & 331 & $62.7 \pm 6.4^{\dagger}$ & $\mathrm{RP}$ & no & $11.1 \pm 10.5^{\dagger}$ & $29.7 \pm 33.2^{\dagger}$ & 7 \\
\hline Whittemore, 2008 [12] & USA & $1988-2003$ & $\mathrm{R}$ & NA & no & 214 & NA & $\mathrm{RP}$ & no & NA & $\mathrm{NA}$ & 5 \\
\hline Wolters, 2009 [13] & Netherland & 1993-2000 & $\mathrm{R}$ & NA & no & 344 & 63.6 & $\mathrm{RP}$ & no & NA & $96.2(0-161)^{*}$ & 6 \\
\hline Yee, 2010 [34] & USA & 2004-2007 & $\mathrm{R}$ & NA & no & 1298 & $59(55-64)$ & $\mathrm{RP}$ & no & $5.1(3.7-7.1)$ & 27 & 8 \\
\hline Yoshimoto, 2008 [35] & Japan & $1997-2000$ & $\mathrm{R}$ & NA & no & 122 & NA & $\mathrm{RP}$ & no & NA & $87.4(11.5-161.6)^{5}$ & 7 \\
\hline
\end{tabular}

R, retrospective; RP, radical prostatectomy; RALP, Robot-Assisted Laparoscopic Radical Prostatectomy; LA, lymphadenectomy (lymph node dissection); SRP, Salvage radical prostatectomy; EBRT, lower doses of radiation from external-beam; NET, endocrine therapy; RT, radiotherapy; NA, not available. "Data in median (range); 'Data in mean \pm SD

\section{Subgroup analysis}

We also underwent the subgroup analyses which categorized by univariate and multivariate analysis; primary and second endpoint; area; year of publication; sample size. The pooled HRs and 95\% CIs were compared in subgroups (Table 3). HRs results of univariate models were much higher than multivariate ones, because the multivariate analyses could include more influencing factors. If the clinicopathologic factor was the primary endpoint of a study, its HR results were uncertain to be higher than the second endpoint counterpart. Prognostic values had no obvious difference between eastern and western, between publication year and the sample size of studies.

\section{DISCUSSION}

Although clinically localized disease can be managed by RP, about $20-30 \%$ of prostate cancer patients may suffer from recurrence which can be detected by rising serum PSA initially. Detectable serum PSA after RP or rising PSA level after PSA detection absence is defined as BCR, which often precedes clinical progression and prostate cancer specific mortality $[5,8]$. High risks of BCR rationalizes the administration of early salvage therapies and more frequent follow-up for patients at lower PSA levels [36]. However, the probability of BCR after $\mathrm{RP}$ is difficult to determine because it may vary according to several baseline risk characteristics and various tumor characteristics. Some traditional clinicopathologic features such as preoperative PSA level, biopsy Gleason score (GS) and tumor staging also show considerable prognostic predictive value and facilitate clinical decisionmaking by taking part in certain nomograms. One of the commonly used preoperative models for prediction of BCR is D'Amico risk stratification scheme which utilizes PSA level, biopsy GS and AJCC T stage [37]. Another predictive model designed by Stephenson et al. evaluates preoperative PSA, clinical stage, biopsy GS, year of surgery, and biopsy cores to determine the risk of BCR after RP [38]. Although these predictive tools have been externally validated, their ability for prediction of BCR needs improvement further. Routine histopathological examination of resected tumor specimens can provide us extensive details which prostate biopsy or biochemical tests can't. Their predictive potential is also underestimated and neglected in significant measure [39]. 
It is still unresolved whether certain tumor characteristics can act as accurate, flexible, and easily accessible factors to assist BCR prediction.

The objective of our meta-analysis was to elucidate the association between dismal clinical detections and biochemical recurrence of prostate cancer after RP. Currently, certain predictive tools are available to predict several survival endpoints in prostate cancer including BCR and some of them have already shown considerable accuracy for predicting risks of progression, recurrence and mortality [40, 41]. However, there exist some limitations which compromise the predictive value. First, some commonly used predictive models like D'Amico risk stratification scheme, the Cancer of the Prostate Risk Assessment (CAPRA) score, and the Stephenson nomogram utilized preoperative variables to obtain the possibility of BCR after RP [40, 42]. Although some clinicopathological features from preoperative biopsy are included in these nomograms, systemic postoperative pathologic examination is capable of providing us more information with more details. Second, some prognostic variables used in these nomograms were simply proved to be significant prognostic factors with Cox proportional hazards models. Further validation of a larger population and pooled predictive value of different cohorts are needed to determine their roles in quantitative manners. In an attempt to settle these limitations, we conducted this meta-analysis to pool relevant studies and figure out the predictive values of several clinicopathological characteristics of postoperative resected specimens for prediction of BCR.

This meta-analysis combined the results from 29 studies of 21,683 patients and revealed that identification of SVI, ECE, PSM, PNI, LNI or LVI could all significantly predict high risks of prostate cancer patients, with the pooled HRs ranging from 1.59 to 2.03 (all $P$-value $\leq 0.0001$ ). Hence, we observed that these pathologic findings were independent risk factors of biochemical recurrence in prostate cancer in this comprehensive meta-analysis. Our results were relatively reliable due to certain advantages. First, number of studies were sufficient and sample sizes were relatively large

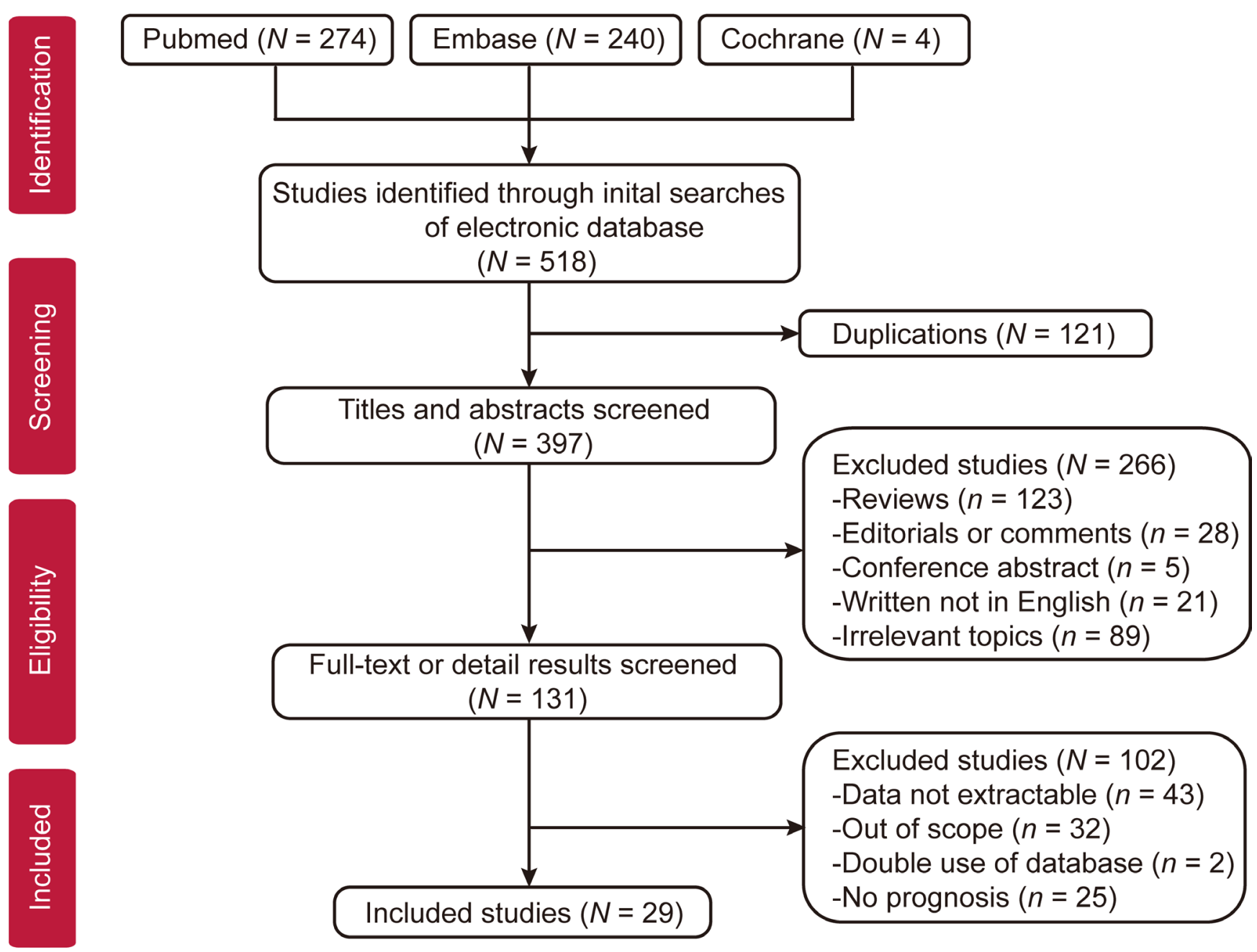

Figure 1: Flow diagram of studies selection. 
Table 2: Overall analyses of pathological factors in biochemical recurrence in prostate cancer after radical prostatectomy

\begin{tabular}{|c|c|c|c|c|c|c|c|c|}
\hline \multirow{2}{*}{ Outcome of interest } & \multirow{2}{*}{ No. of studies } & \multirow{2}{*}{$\operatorname{HR}(95 \% \mathrm{CI})$} & \multirow{2}{*}{$p$-value } & \multicolumn{4}{|c|}{ Study heterogeneity } & \multirow{2}{*}{$\begin{array}{l}\text { Effect } \\
\text { Model }\end{array}$} \\
\hline & & & & $\mathrm{Chi}^{2}$ & df & $I^{2}$ & $p$-value & \\
\hline \multicolumn{9}{|l|}{ SVI } \\
\hline Total Analysis & $1,2,4,6,9-16,18-25,29$ & $1.97[1.79,2.18]$ & $<0.00001$ & 32.86 & 22 & $33 \%$ & 0.06 & Fixed \\
\hline Univariate Analysis & $\begin{array}{c}1,2,4,6 \\
9-12,16,19,20,23,24,27,29\end{array}$ & $3.61[2.80,4.66]$ & $<0.00001$ & 48.04 & 13 & $73 \%$ & $<0.00001$ & Random \\
\hline Multivariate Analysis & $\begin{array}{c}1,2,4,6,10,11,13-16,18 \\
20-25,27,28\end{array}$ & $1.93[1.73,2.14]$ & $<0.00001$ & 27.61 & 18 & $35 \%$ & 0.07 & Fixed \\
\hline \multicolumn{9}{|l|}{ PSM } \\
\hline Total Analysis & $1-3,6,8-16,20-29$ & $1.79[1.56,2.06]$ & $<0.00001$ & 40.61 & 22 & $46 \%$ & 0.009 & Random \\
\hline Univariate Analysis & $1,2,4,6,9-12,16,20,23,24,27,29$ & $2.34[2.09,2.63]$ & $<0.00001$ & 46.60 & 13 & $72 \%$ & $<0.0001$ & Random \\
\hline Multivariate Analysis & $1,3,6,8,10,11,13-16,20-28$ & $1.91[1.66,2.20]$ & $<0.00001$ & 32.71 & 18 & $45 \%$ & 0.02 & Random \\
\hline \multicolumn{9}{|l|}{ ECE } \\
\hline Total Analysis & $2,4,6,8-11,13-16,20-25,28,29$ & $2.03[1.65,2.50]$ & $<0.00001$ & 52.38 & 18 & $66 \%$ & $<0.0001$ & Random \\
\hline Univariate Analysis & $2,4,6,9-11,16,20,23,24,29$ & $3.44[2.63,4.52]$ & $<0.00001$ & 39.49 & 10 & $75 \%$ & $<0.0001$ & Random \\
\hline Multivariate Analysis & $\begin{array}{l}4,6,8-11,13-16 \\
20-22,24,25,28\end{array}$ & $1.93[1.61,2.31]$ & $<0.00001$ & 26.24 & 15 & $43 \%$ & 0.04 & Random \\
\hline \multicolumn{9}{|l|}{ LVI } \\
\hline Total Analysis & $\begin{array}{c}2,3,5,7,9,10,11,14,15,17,18,20 \\
23,24,26,28,29\end{array}$ & $1.85[1.54,2.22]$ & $<0.00001$ & 32.30 & 16 & $50 \%$ & 0.009 & Random \\
\hline Univariate Analysis & $2,5,7,9,10,11,17,20,23,24$ & $2.73[1.90,3.94]$ & $<0.00001$ & 41.34 & 9 & $78 \%$ & $<0.00001$ & Random \\
\hline Multivariate Analysis & $\begin{array}{c}2,3,9,10,14,15,18,20,23,24,2 \\
6,28,29\end{array}$ & $1.85[1.48,2.33]$ & $<0.00001$ & 30.48 & 12 & $61 \%$ & 0.002 & Random \\
\hline \multicolumn{9}{|l|}{ LNI } \\
\hline Total Analysis & $1,2,6,11,14-16,22-26,28$ & $1.88[1.37,2.60]$ & 0.0001 & 72.04 & 12 & $83 \%$ & $<0.00001$ & Random \\
\hline Univariate Analysis & $1,2,6,11,16,23,24$ & $6.09[3.29,11.27]$ & $<0.00001$ & 47.31 & 6 & $87 \%$ & $<0.00001$ & Random \\
\hline Multivariate Analysis & $1,2,6,11,14-16,22-26,28$ & $1.88[1.37,2.60]$ & 0.0001 & 72.04 & 12 & $83 \%$ & $<0.00001$ & Random \\
\hline \multicolumn{9}{|l|}{ PIN } \\
\hline Total & $2,5,8-11,16,20,23,24,26,29$ & $1.59[1.33,1.91]$ & $<0.00001$ & 14.44 & 11 & $24 \%$ & 0.21 & Fixed \\
\hline Univariate Analysis & $2,5,9-11,16,20,23,24,29$ & $2.29[1.92,2.73]$ & $<0.00001$ & 7.72 & 9 & $0 \%$ & 0.56 & Fixed \\
\hline Multivariate Analysis & $8,10,11,20,23,24,26$ & $1.39[1.12,1.74]$ & 0.003 & 3.96 & 6 & $0 \%$ & 0.68 & Fixed \\
\hline
\end{tabular}

$\mathrm{CI}=$ Confidence interval; $\mathrm{HR}=$ hazard ratio; $\mathrm{LVI}=$ lymphovascular invasion; $\mathrm{PNI}=$ perineural invasion; $\mathrm{SVI}=$ seminal vesicle invasion; $\mathrm{ECE}=$ extracapular extension; LNI = lymph node involvement; PSM = positive surgical margin.

"Statistically significant results are shown in bold.

even after rigorous evaluation and selection of eligible studies. Second, no obvious heterogeneity and publication bias between the studies were found, subgroup analyses were also included to obviate potential confounding factor. Third, we chose a panel of clinicopathological variables which were recommended to report regularly in postoperative setting. These variables jointly were a reflection of tumor expansion and invasiveness. However, we must acknowledge that there existed potential intrinsic weaknesses in these trials contained in our metaanalysis. Most studies included in our meta-analysis were retrospective observations, without any prospective random controlled trials. Besides, due to limited data on effect of six predictors on tumor metastasis and mortality, a single survival endpoint BCR was adopted. This might limit the overall significance of our pooled results. Last, in the overall analysis of pooled HRs and $95 \%$ CIs, we accepted the outcomes of univariate Cox models when the multivariate ones were absent, so the final predictive effects could be affected by the less reliable results of univariate analyses.

In conclusion, our pooled results prove that all the six clinicopathological features we discussed can predict early BCR in patients with prostate cancer after RP. Tumor characteristics are promising prognostic factors for BCR prediction. The clinicopathological findings may be integrated into a comprehensive, reliable, and handy predictive tool with strong ability to predict patient outcome after surgical resection. Further well-designed prospective studies will offer more reliable conclusions on the predictive value of certain postoperative pathological characteristics for BCR in prostate cancer patients. 


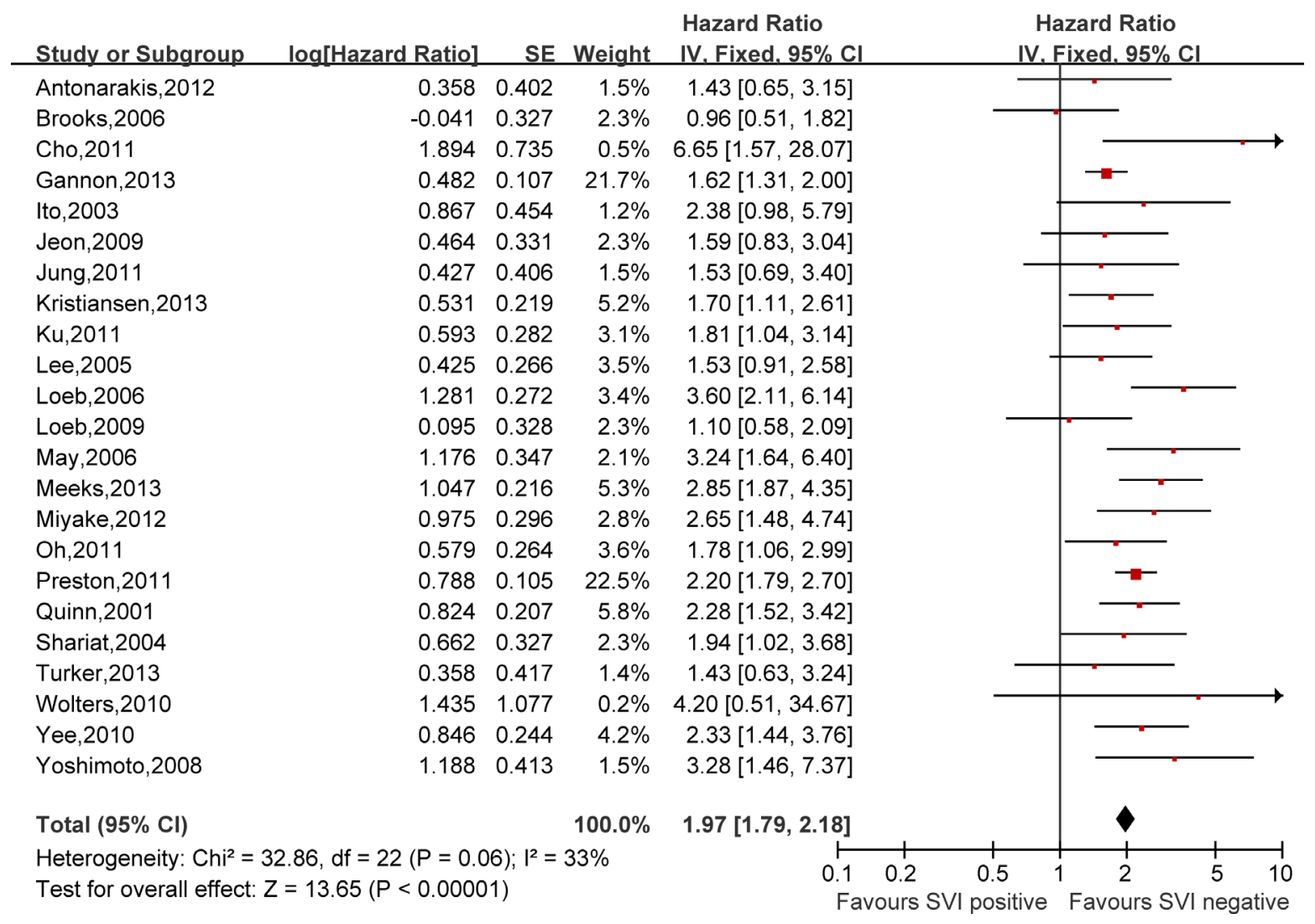

Figure 2: Meta-analysis of the prognostic values of SVI in prostate cancer after RP.

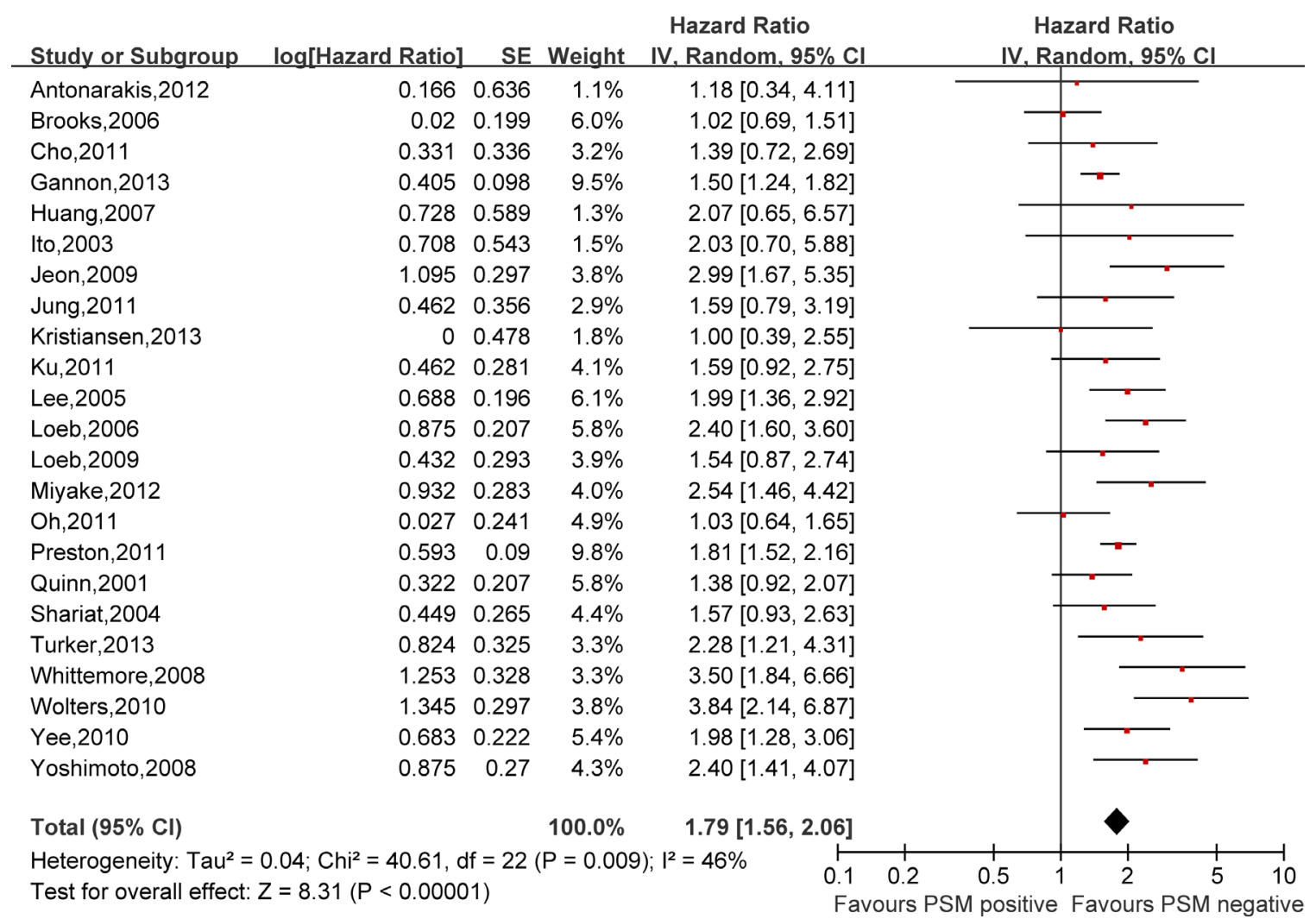

Figure 3: Meta-analysis of the prognostic values of PSM in prostate cancer after RP. 


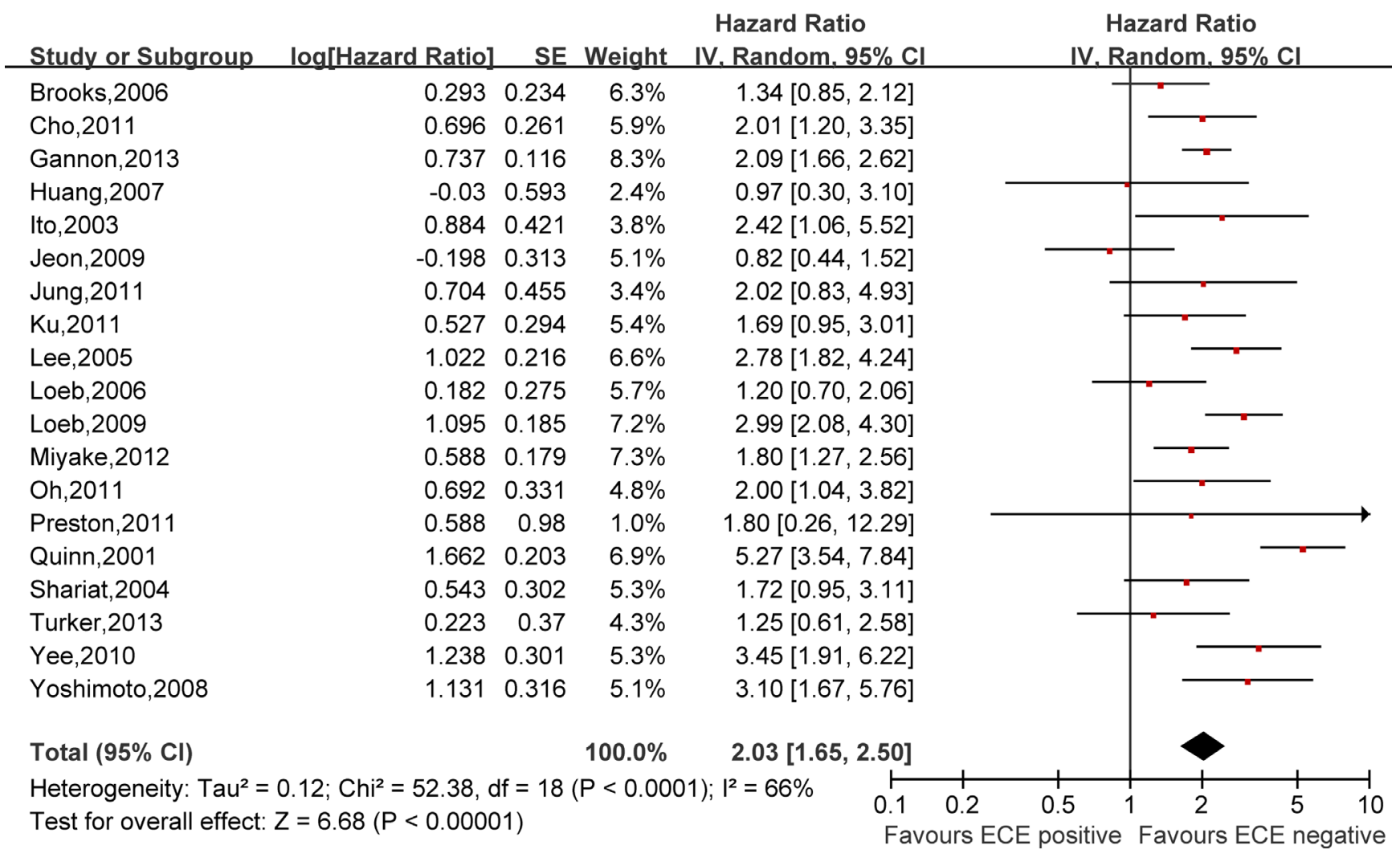

Figure 4: Meta-analysis of the prognostic values of ECE in prostate cancer after RP.

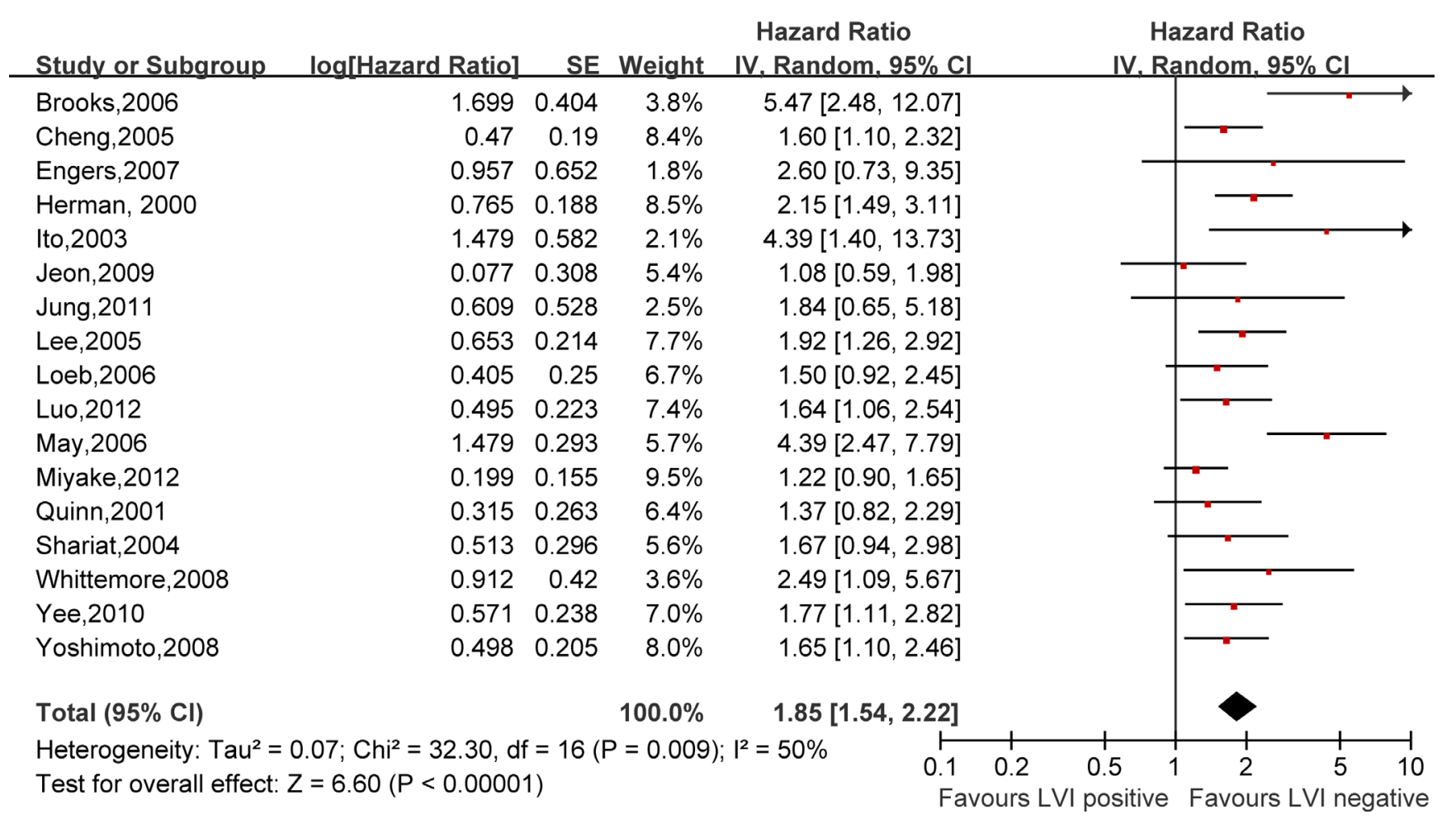

Figure 5: Meta-analysis of the prognostic values of LVI in prostate cancer after RP. 
Table 3: Subgroup analysis

\begin{tabular}{|c|c|c|c|c|c|c|}
\hline & LVI & PNI & SVI & ECE & LNI & PSM \\
\hline Overall & $1.85[1.54,2.22]$ & $1.59[1.33,1.91]$ & $1.97[1.79,2.18]$ & $2.03[1.65,2.50]$ & $1.88[1.37,2.60]$ & $1.79[1.56,2.06]$ \\
\hline \multicolumn{7}{|l|}{ HR analysis } \\
\hline Univariate & $2.73[1.90,3.94]$ & $2.29[1.92,2.73]$ & $3.61[2.80,4.66]$ & $3.44[2.63,4.52]$ & $6.09[3.29,11.27]$ & $2.34[2.09,2.63]$ \\
\hline Multivariate & $1.85[1.48,2.33]$ & $1.39[1.12,1.74]$ & $1.93[1.73,2.14]$ & $1.95[1.61,2.36]$ & $1.88[1.37,2.60]$ & $1.91[1.66,2.20]$ \\
\hline \multicolumn{7}{|l|}{ Endpoint } \\
\hline Primary endpoint & $2.05[1.64,2.58]$ & $2.28[1.62,3.21]$ & $2.21[1.63,2.99]$ & $1.80[0.26,12.29]$ & l & / \\
\hline Second endpoint & $1.44[1.18,1.76]$ & $1.38[1.12,1.72]$ & $1.95[1.76,2.16]$ & $2.03[1.65,2.51]$ & $1.88[1.37,2.60]$ & $1.79[1.56,2.06]$ \\
\hline \multicolumn{7}{|l|}{ Area } \\
\hline Eastern & $1.46[1.24,1.72]$ & $1.50[1.20,1.88]$ & $2.13[1.73,2.62]$ & $2.03[1.41,2.92]$ & $3.06[1.79,5.25]$ & $1.91[1.45,2.52]$ \\
\hline Western & $2.26[1.74,2.93]$ & $1.79[1.31,2.44]$ & $1.93[1.73,2.16]$ & $2.02[1.58,2.58]$ & $1.73[1.23,2.43]$ & $1.69[1.53,1.87]$ \\
\hline \multicolumn{7}{|l|}{ Year of publication } \\
\hline$\geq 2010$ & $1.44[1.16,1.79]$ & $1.85[1.19,2.87]$ & $1.96[1.75,2.20]$ & $2.01[1.72,2.34]$ & $2.33[1.98,2.74]$ & $1.70[1.53,1.89]$ \\
\hline$<2010$ & $2.00[1.59,2.50]$ & $1.49[1.14,1.94]$ & $1.99[1.50,2.63]$ & $2.02[1.38,2.96]$ & $1.62[1.12,2.35]$ & $1.82[1.56,2.12]$ \\
\hline \multicolumn{7}{|l|}{ Sample } \\
\hline$>300$ & $1.72[1.37,2.16]$ & $1.48[1.18,1.86]$ & $1.96[1.76,2.18]$ & $2.29[1.75,2.99]$ & $1.44[1.30,1.58]$ & $1.71[1.55,1.89]$ \\
\hline$\leq 300$ & $1.95[1.60,2.37]$ & $1.81[1.34,2.45]$ & $2.04[1.61,2.57]$ & $1.75[1.27,2.40]$ & $2.04[1.16,3.60]$ & $1.94[1.43,2.62]$ \\
\hline
\end{tabular}

$\mathrm{LVI}=$ lymphovascular invasion; PNI = perineural invasion; SVI = seminal vesicle invasion; $\mathrm{ECE}$ = extracapular extension; $\mathrm{LNI}=$ lymph node involvement; $\mathrm{PSM}=$ positive surgical margin .

\section{MATERIALS AND METHODS}

All methods for this systematic review and metaanalysis are outlined in a prospectively registered protocol available online (PROSPERO identifier CRD42017057810), and reporting follows PRISMA (Preferred Reporting Items for Systematic Reviews and Meta-Analyses) guidelines.

\section{Eligibility criteria}

Eligible studies include randomised, controlled trials and nonrandomised studies (observational, cohort) that have investigated the treatment with radical prostatectomy, in participants over 36 years old with prostate cancer. Studies must have reported data on at least one of SVI, PSM, ECE, LVI, LNI and PNI.

\section{Search strategy}

We searched published studies indexed in PubMed, Embase, Cochrane Library and the China National Knowledge Infrastructure databases until Oct 31, 2016. The search query are as follow: (('SVI' or 'ECE' or 'PSM' or 'PNI' or 'LNI' or 'LVI') and ('biochemical recurrence') and ('prostate cancer' or 'prostate carcinoma' or 'prostatic carcinoma') and ('radical prostatectomy')). All the

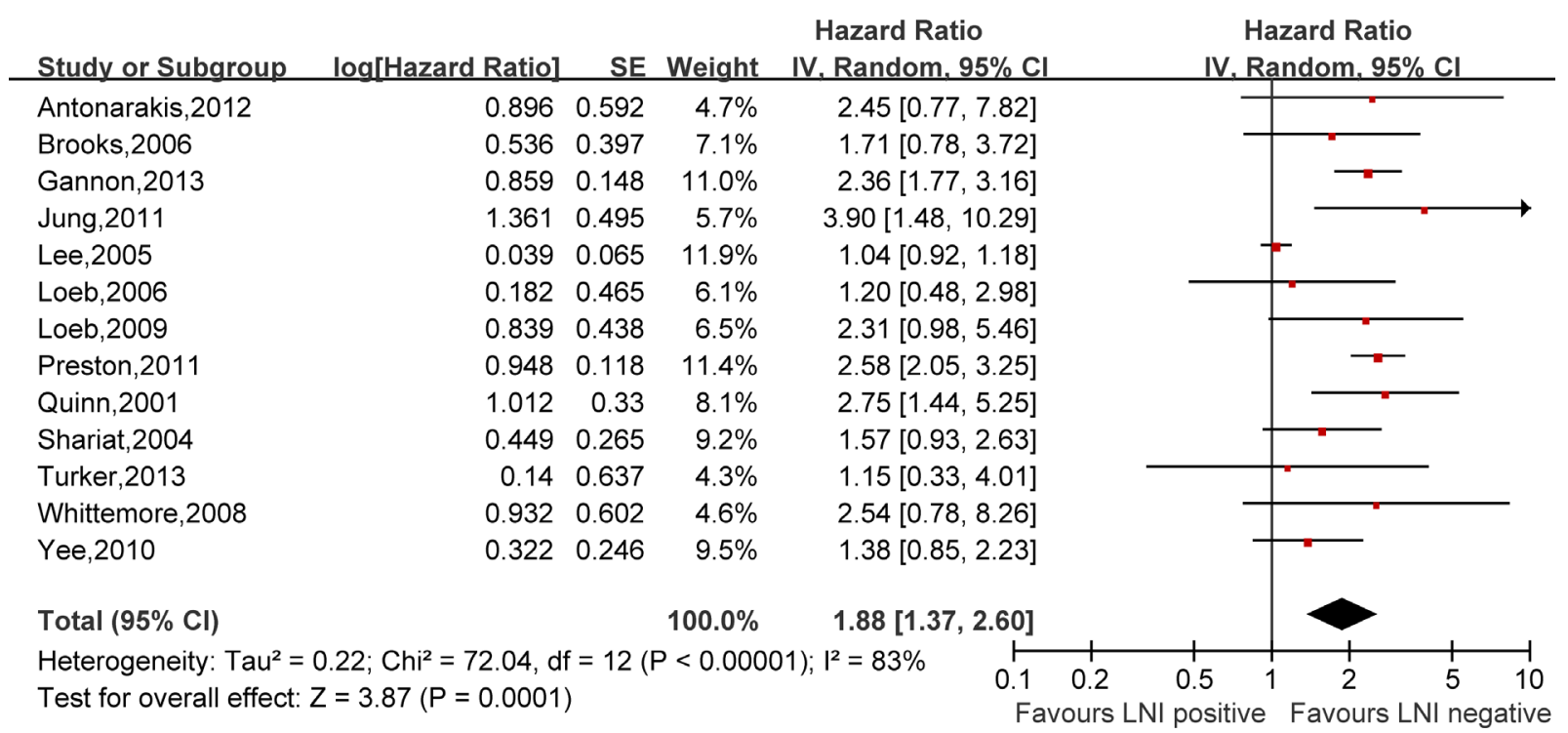

Figure 6: Meta-analysis of the prognostic values of LNI in prostate cancer after RP. 
eligible papers were published in English. Following the literature search, all duplicates were excluded. References from review articles, commentaries, editorials, included studies, and conference publications of relevant medical societies were reviewed and cross-referenced to ensure completeness. Conference abstracts were excluded.

\section{Study selection}

Studies were included if they satisfied all the following requirements according to the PICOS criteria: (1) included paitents who were pathologically confirmed with prostate cancer patients and received radical prostatectomy; (2) for intervention, radical prostatectomy, either laparoscopic radical prostatectomies or robotic assisted radical prostatectomies was performed; (3) outcomes at least reported BCFS in prostate cancer patients after RP. (4) clinicopathological features assessing prognosis at least included one of SVI, PSM, ECE, LVI, LNI and PNI. (5) Results must report the sample size, hazard ratios (HR) combined with $95 \%$ confidence intervals; (6) studies had to be original articles.

Studies were excluded if any of the following criteria were met: (1) review articles, guidelines, consensus statements, letters, editorials, and conference abstracts; (2) studies with overlapping patient population; (3) studies which didn't provide enough data for HR and standard error (SE) estimation; (4) non-English paper.

Two reviewers (L.H.R. and Z.H.) independently evaluated the eligibility of the selected studies from the literature. Disagreements were resolved by consensus via discussion with a third reviewer (Y.Z.Q.).

\section{Data extraction and quality assessment}

For each of eligible study, information was extracted and cross-checked by two independent investigators: (1) baseline characteristics: information of first author, year of publication, study design type, study location, period of recruitment, survival definition, sample size, age, operative procedures, adjuvant therapies, pre-operative PSA level, duration of follow-up; (2) survival analysis: end-point, patient numbers and percentage of specific pathological traits, hazard ratios (HR) combined with $95 \%$ confidence intervals $(\mathrm{CI})$ and $P$ value of univariate and multivariate analysis, primary endpoint and co-factors of Cox's proportional hazards regression models.

Newcastle-Ottawa quality assessment scale for all eligible studies was used to evaluate methodological quality. Data extraction and quality assessment were performed independently by two reviewers (Y.T. and L.H.Y.). Discrepancies between the two inquirers in data extraction were resolved by discussion and consultation with a consensus (Y.Z.Q.) to reach a consensus.

\section{Outcomes of interest and survival end-points}

The primary outcome measures used in articles were the biochemical recurrence-free survival rate (BCFS). Actually, the progression-free survival (PFS) and diseasefree survival (DFS) used in specific studies were always equivalent to BCFS with the same definition of survival. For the convenience of studying, we chose BCFS as the single survival end-points. For assessing BCFS, recurrence of the disease was referred to $\mathrm{BCR}$, most often regarded as postoperative serum PSA at least $0.2 \mathrm{ng} / \mathrm{mL}$.

\section{HR pooled and statistical analysis}

HRs and 95\% CIs were employed to assess the predictive significance of six clinicopathological events on BCFS of the sick people. A pooled HR $>1$ indicated a worse survival of positive group compared to the negative group. For studies which did not report HRs directly, figures

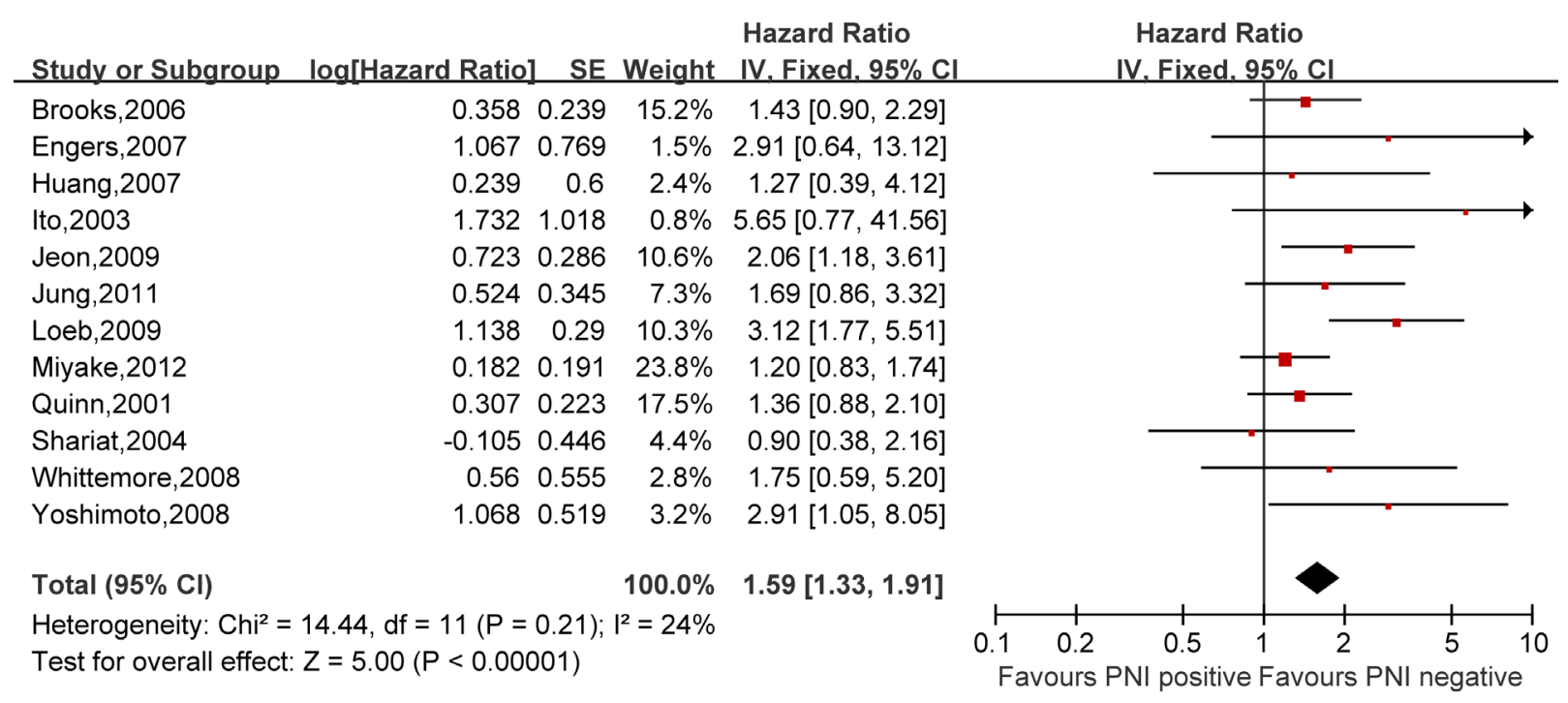

Figure 7: Meta-analysis of the prognostic values of PNI in prostate cancer after RP. 
and data in primary papers were employed to work out the HRs based on the methods proposed by Tiernry [43].

We employed Review Manager Software (RevMan 5.3, Cochrane Collaboration, Oxford, UK) to make our meta-analysis. Total analyses of specific pathological factors were conducted using results of multivariate models and univariate results when the multivariate ones were not available.

\section{Assessment of heterogeneity}

We employed a chi $^{2}$-based test for assessment of homogeneity and inconsistency index $\left(\mathrm{I}^{2}\right)$ statistic. Furthermore, we employed random effects models for each of our analyses given the identified clinical heterogeneity [44]. The heterogeneity of combined HRs were respectively evaluated with the help of graphic examination of forest plots, and funnel plots were utilized to explore any potential publication bias.

\section{Subgroup analysis}

To wipe off the effect of other confounding factors, we performed the subgroup analysis categorized by univariate or multivariate analysis, primary or second endpoint, area location (Eastern/Western), publication year $(\geq 2010 /<2010)$ and sample Size $(>300 / \leq 300)$. The pooled HRs with their 95\% CIs were elevated separately, and compared in subgroups. Then the heterogeneity between studies might be understood and managed better.

\section{Abbreviations}

RP: radical prostatectomy; RALP: RobotAssisted Laparoscopic Radical Prostatectomy; LA: lymphadenectomy (lymph node dissection); LVI: lymphovascular invasion; PNI: perineural invasion; SVI: seminal vesicle invasion; ECE: extracapular extension; LNI: lymph node involvement; PSM: positive surgical margin; pre-op PSA: preoperative PSA level; GS: Gleason score; HGPIN: High-grade prostatic intraepithelial neoplasia; pT: pathologic stage; pTI: percentage of tumor involvement; EBRT: lower doses of radiation from external-beam RT; RT: radiotherapy; P: prospective; R: retrospective; CI: Confidence interval; HR: hazard ratio; NA: not available.

\section{Author contributions}

LHR conceived and designed the review and wrote the manuscript. ZH wrote the manuscript. TK carried out the literature search and selection. YT performed data extraction and data analysis. LHY contributed to data extraction, quality assessment and resolved the disagreement. SXF contributed to data extraction and designing figures. YZQ supervised the data collection, statistical analysis and critically amended the manuscript. XH contributed to the study layout, manuscript revising and study surveillance. All authors read and recognized the final manuscript.

\section{ACKNOWLEDGMENTS AND FUNDING}

We thank all the patients and clinical researchers who are involved in the studies chosen in the metaanalysis. This work was supported by the National Natural Science Foundation of China (31372562, 81270788, $81470935,81370805,81402098,81402087)$, the National Major Scientific and Technological Special Project for Significant New Drugs Development (2012ZX09303018), the Chenguang Program of Wuhan Science and Technology Bereau (2015070404010199), and The National High Technology Research and Development Program 863 (2014AA020607).

\section{CONFLICTS OF INTEREST}

The authors declare no conflicts of interest.

\section{REFERENCES}

1. Williams S, Chiong E, Lojanapiwat B, Umbas R, Akaza H, Asian Oncology Summit 2013. Management of prostate cancer in Asia: resource-stratified guidelines from the Asian Oncology Summit 2013. The Lancet Oncology. 2013; 14:e524-534.

2. Punnen S, Cooperberg MR. The epidemiology of highrisk prostate cancer. Current opinion in urology. 2013; 23:331-336.

3. Gnanapragasam VJ, Mason MD, Shaw GL, Neal DE. The role of surgery in high-risk localised prostate cancer. BJU international. 2012; 109:648-658.

4. Novara G, Ficarra V, Mocellin S, Ahlering TE, Carroll PR, Graefen M, Guazzoni G, Menon M, Patel VR, Shariat SF, Tewari AK, Van Poppel H, Zattoni F, et al. Systematic review and meta-analysis of studies reporting oncologic outcome after robot-assisted radical prostatectomy. European urology. 2012; 62:382-404.

5. Berney DM, Wheeler TM, Grignon DJ, Epstein JI, Griffiths DF, Humphrey PA, van der Kwast T, Montironi R, Delahunt B, Egevad L, Srigley JR, and ISUP Prostate Cancer Group. International Society of Urological Pathology (ISUP) Consensus Conference on Handling and Staging of Radical Prostatectomy Specimens. Working group 4: seminal vesicles and lymph nodes. Modern pathology. 2011; 24:39-47.

6. Huang SP, Huang CY, Wang JS, Liu CC, Pu YS, Yu HJ, Yu CC, Wu TT, Huang CH, Wu WJ, Chou YH, Wu MT. Prognostic significance of $\mathrm{p} 53$ and $\mathrm{X}$-ray repair crosscomplementing group 1 polymorphisms on prostatespecific antigen recurrence in prostate cancer post radical prostatectomy. Clinical cancer research. 2007; 13:6632-6638. 
7. Loeb S, Epstein JI, Humphreys EB, Walsh PC. Does perineural invasion on prostate biopsy predict adverse prostatectomy outcomes? BJU international. 2010; 105:1510-1513.

8. Boorjian SA, Tollefson MK, Thompson RH, Rangel LJ, Bergstralh EJ, Karnes RJ. Natural history of biochemical recurrence after radical prostatectomy with adjuvant radiation therapy. The Journal of urology. 2012; 188:1761-1766.

9. Quinn DI, Henshall SM, Haynes AM, Brenner PC, Kooner R, Golovsky D, Mathews J, O’Neill GF, Turner JJ, Delprado W, Finlayson JF, Sutherland RL, Grygiel JJ, et al. Prognostic significance of pathologic features in localized prostate cancer treated with radical prostatectomy: implications for staging systems and predictive models. Journal of clinical oncology. 2001; 19:3692-3705.

10. Shariat SF, Khoddami SM, Saboorian H, Koeneman KS, Sagalowsky AI, Cadeddu JA, McConnell JD, Holmes MN, Roehrborn CG. Lymphovascular invasion is a pathological feature of biologically aggressive disease in patients treated with radical prostatectomy. The Journal of urology. 2004; 171:1122-1127.

11. Turker P, Bas E, Bozkurt S, Gunlusoy B, Sezgin A, Postaci $\mathrm{H}$, Turkeri L. Presence of high grade tertiary Gleason pattern upgrades the Gleason sum score and is inversely associated with biochemical recurrence-free survival. Urologic oncology. 2013; 31:93-98.

12. Whittemore DE, Hick EJ, Carter MR, Moul JW, MirandaSousa AJ, Sexton WJ. Significance of tertiary Gleason pattern 5 in Gleason score 7 radical prostatectomy specimens. The Journal of urology. 2008; 179:516-522.

13. Wolters T, Roobol MJ, van Leeuwen PJ, van den Bergh RC, Hoedemaeker RF, van Leenders GJ, Schroder FH, van der Kwast TH. Should pathologists routinely report prostate tumour volume? The prognostic value of tumour volume in prostate cancer. European urology. 2010; 57:821-829.

14. Antonarakis ES, Keizman D, Zhang Z, Gurel B, Lotan TL, Hicks JL, Fedor HL, Carducci MA, De Marzo AM, Eisenberger MA. An immunohistochemical signature comprising PTEN, MYC, and Ki67 predicts progression in prostate cancer patients receiving adjuvant docetaxel after prostatectomy. Cancer. 2012; 118:6063-6071.

15. Brooks JP, Albert PS, O’Connell J, McLeod DG, Poggi MM. Lymphovascular invasion in prostate cancer: prognostic significance in patients treated with radiotherapy after radical prostatectomy. Cancer. 2006; 106:1521-1526.

16. Cheng L, Jones TD, Lin H, Eble JN, Zeng G, Carr MD, Koch MO. Lymphovascular invasion is an independent prognostic factor in prostatic adenocarcinoma. The Journal of urology. 2005; 174:2181-2185.

17. Cho IC, Kwon WA, Kim JE, Joung JY, Seo HK, Chung J, Park WS, Lee KH. Prostate volume has prognostic value only in pathologic $\mathrm{T} 2$ radical prostatectomy specimens. Journal of Korean medical science. 2011; 26:807-813.

18. Engers R, Ziegler S, Mueller M, Walter A, Willers R, Gabbert HE. Prognostic relevance of increased Rac GTPase expression in prostate carcinomas. Endocrine-related cancer. 2007; 14:245-256.

19. Gannon PO, Lessard L, Stevens LM, Forest V, Begin LR, Minner S, Tennstedt P, Schlomm T, Mes-Masson AM, Saad F. Large-scale independent validation of the nuclear factor-kappa B p65 prognostic biomarker in prostate cancer. European journal of cancer. 2013; 49:2441-2448.

20. Herman CM, Wilcox GE, Kattan MW, Scardino PT, Wheeler TM. Lymphovascular invasion as a predictor of disease progression in prostate cancer. The American journal of surgical pathology. 2000; 24:859-863.

21. Ito K, Nakashima J, Mukai M, Asakura H, Ohigashi T, Saito S, Tachibana M, Hata J, Murai M. Prognostic implication of microvascular invasion in biochemical failure in patients treated with radical prostatectomy. Urologia internationalis. 2003; 70:297-302.

22. Jeon HG, Bae J, Yi JS, Hwang IS, Lee SE, Lee E. Perineural invasion is a prognostic factor for biochemical failure after radical prostatectomy. International journal of urology. 2009; 16:682-686.

23. Jung JH, Lee JW, Arkoncel FR, Cho NH, Yusoff NA, Kim KJ, Song JM, Kim SJ, Rha KH. Significance of perineural invasion, lymphovascular invasion, and high-grade prostatic intraepithelial neoplasia in robot-assisted laparoscopic radical prostatectomy. Annals of surgical oncology. 2011; 18:3828-3832.

24. Kristiansen A, Wiklund F, Wiklund P, Egevad L. Prognostic significance of patterns of seminal vesicle invasion in prostate cancer. Histopathology. 2013; 62:1049-1056.

25. $\mathrm{Ku}$ JH, Jeong CW, Park YH, Cho MC, Kwak C, Kim HH. Biochemical recurrence after radical prostatectomy with or without pelvic lymphadenectomy in Korean men with highrisk prostate cancer. Japanese journal of clinical oncology. 2011; 41:656-662.

26. Lee KL, Marotte JB, Ferrari MK, McNeal JE, Brooks JD, Presti JC Jr. Positive family history of prostate cancer not associated with worse outcomes after radical prostatectomy. Urology. 2005; 65:311-315.

27. Loeb S, Roehl KA, Yu X, Antenor JA, Han M, Gashti SN, Yang XJ, Catalona WJ. Lymphovascular invasion in radical prostatectomy specimens: prediction of adverse pathologic features and biochemical progression. Urology. 2006; 68:99-103.

28. Luo HL, Chiang PH, Chen YT, Cheng YT. Lymphovascular invasion is a pathological feature related to aggressive cancer behavior and predicts early recurrence in prostate cancer. The Kaohsiung journal of medical sciences. 2012; 28:327-330.

29. May M, Kaufmann O, Hammermann F, Loy V, Siegsmund M. Prognostic impact of lymphovascular invasion in radical prostatectomy specimens. BJU international. 2007; 99:539-544.

30. Meeks JJ, Walker M, Bernstein M, Eastham JA. Seminal vesicle involvement at salvage radical prostatectomy. BJU international. 2013; 111:E342-347. 
31. Miyake H, Muramaki M, Furukawa J, Tanaka H, Inoue TA, Fujisawa M. Prognostic significance of primary Gleason pattern in Japanese men with Gleason score 7 prostate cancer treated with radical prostatectomy. Urologic oncology. 2013; 31:1511-1516.

32. Oh JJ, Lee SC, Jeong CW, Yoon CY, Jeong SJ, Hong SK, Byun SS, Rho YK, Choe G, Lee SE. The prognostic significance of percentage of tumour involvement according to disease risk group in men treated with radical prostatectomy. Asian journal of andrology. 2011; 13:828-832.

33. Preston MA, Carriere M, Raju G, Morash C, Doucette S, Gerridzen RG, Bella AJ, Eastham JA, Scardino PT, Cagiannos I. The prognostic significance of capsular incision into tumor during radical prostatectomy. European urology. 2011; 59:613-618.

34. Yee DS, Shariat SF, Lowrance WT, Maschino AC, Savage CJ, Cronin AM, Scardino PT, Eastham JA. Prognostic significance of lymphovascular invasion in radical prostatectomy specimens. BJU international. 2011; 108:502-507.

35. Yoshimoto M, Joshua AM, Cunha IW, Coudry RA, Fonseca FP, Ludkovski O, Zielenska M, Soares FA, Squire JA. Absence of TMPRSS2:ERG fusions and PTEN losses in prostate cancer is associated with a favorable outcome. Modern pathology. 2008; 21:1451-1460.

36. Fine SW, Amin MB, Berney DM, Bjartell A, Egevad L, Epstein JI, Humphrey PA, Magi-Galluzzi C, Montironi R, Stief C. A contemporary update on pathology reporting for prostate cancer: biopsy and radical prostatectomy specimens. European urology. 2012; 62:20-39.
37. Egevad L. Handling of radical prostatectomy specimens. Histopathology. 2012; 60:118-124.

38. Shariata SF, Karakiewiczb PI, Margulisa V, Kattan MW. Inventory of prostate cancer predictive tools. Current Opinion in Urology. 2008; 18:279-296.

39. Lughezzani G, Briganti A, Karakiewicz PI, Kattan MW, Montorsi F, Shariat SF, Vickers AJ. Predictive and prognostic models in radical prostatectomy candidates: a critical analysis of the literature. European urology. 2010; 58:687-700.

40. Thompson J, Lawrentschuk N, Frydenberg M, Thompson L, Stricker P, USANZ. The role of magnetic resonance imaging in the diagnosis and management of prostate cancer. BJU international. 2013 (Suppl 2); 112:6-20.

41. Kattan MW, Wheeler TM, Scardino PT. Postoperative nomogram for disease recurrence after radical prostatectomy for prostate cancer. Journal of clinical oncology. 1999; 17:1499-1507.

42. Stephenson AJ, Scardino PT, Eastham JA, Bianco FJ Jr, Dotan ZA, DiBlasio CJ, Reuther A, Klein EA, Kattan MW. Postoperative nomogram predicting the 10 -year probability of prostate cancer recurrence after radical prostatectomy. Journal of clinical oncology. 2005; 23:7005-7012.

43. Tierney JF, Stewart LA, Ghersi D, Burdett S, Sydes MR. Practical methods for incorporating summary time-to-event data into meta-analysis. Trials. 2007; 8:16.

44. Higgins JPT, Thompson SG, Deeks JJ, Altman DG. Inconsistency in meta-analysis. British Medical Journal. $2003 ; 327: 557-560$. 